\title{
High Temperature Thermodynamic Data for CdTe(c)
}

\author{
Robert F. Brebrick
}

(Submitted May 5, 2009; in revised form October 15, 2009)

\begin{abstract}
The high temperature heat capacity, Gibbs energy of formation, and standard enthalpy and entropy of formation at $298 \mathrm{~K}$ are combined with thermodynamic data for $\mathrm{Cd}$ and revised data for Te to provide an internally consistent data set for $\mathrm{CdTe}(\mathrm{c})$. Equations are given for the Gibbs energy of formation from $\mathrm{Cd}(\mathrm{g})$ and $\mathrm{Te}_{2}(\mathrm{~g})$ and from the solid or liquid elements as a function of temperature. These give values similar to those used before. However, the derived enthalpy and entropy of formation are significantly different due to a revised heat capacity for $\mathrm{CdTe}(\mathrm{c})$. $\mathrm{The}$ standard enthalpy and entropy of formation at $298.15 \mathrm{~K}$ from the gases are $-293262 \mathrm{~J} / \mathrm{mol}$ and $-200.593 \mathrm{~J} / \mathrm{mol} \mathrm{K}$, respectively. From the solid elements they are -100270 and -4.5334 .
\end{abstract}

Keywords material properties, thermodynamic properties

\section{Introduction}

Recently, high temperature heat capacity determinations for $\mathrm{CdTe}(\mathrm{c})$ by Malkova et al. ${ }^{[1]}$ and by Yamaguchi et al. ${ }^{[2]}$ and by others at lower temperatures have been reviewed by Pavlova et al. ${ }^{[3]}$ Here we wish to extend this study of the thermodynamic properties of $\mathrm{CdTe}(\mathrm{c})$ to include experimental values for the high temperature Gibbs energy of formation. The standard enthalpy and entropy of formation at 298.15 are also required, but both are fairly well established. Earlier assessments of the entire Cd-Te system by Jianrong et al. ${ }^{[4]}$ in 1995 and by the author and coworkers. ${ }^{[5,6]}$ depended in part on an estimate of the heat capacity of $\mathrm{CdTe}(\mathrm{c})$ made by Mills. ${ }^{[7]}$ which was based on the heat content measurements by Mezaki et al. ${ }^{[8]}$ According to Pavlova et al., ${ }^{[3]}$ this heat capacity is high by as much as $15 \mathrm{~J} / \mathrm{mol} \mathrm{K}$ at the $1365 \mathrm{~K}$ melting point. Besides, assessments of the entire system are more complicated than necessary to establish the thermodynamic properties of the $\mathrm{CdTe}(\mathrm{c})$ phase itself. For our purposes, the properties of cadmium and tellurium are of course required. Those of cadmium are well established. For tellurium, we use this author's third law analysis ${ }^{[9]}$ of the crystal-liquid-vapor equilibrium for Te. A heat capacity for the liquid determined by Medzhidov and Rasulov ${ }^{[10]}$ was used which is much different than that used in previous thermodynamic calculations. A review of the heat capacity of Te by Davydov et al. ${ }^{[1]}$ was shown ${ }^{[12]}$ to give closely similar results.

Robert F. Brebrick, Department of Mechanical Engineering, Marquette University, Milwaukee, WI 53233, USA. Contact e-mail: rbrebrick@milwpc.com.

\section{Formation of $\mathrm{CdTe}(\mathrm{c})$ from Its $\mathrm{Cd}(\mathrm{g})$ and $\mathrm{Te}_{2}(\mathrm{~g})$}

\subsection{Partial Pressure Data}

The predominant vapor species over $\mathrm{CdTe}(\mathrm{c})$ are cadmium and diatomic tellurium. The partial pressures of $\mathrm{Cd}(\mathrm{g})$ and $\mathrm{Te}_{2}(\mathrm{~g})$ over congruently subliming $\mathrm{CdTe}(\mathrm{c})$ have been determined by measuring the UV-VIS optical absorbance of the coexisting vapor. ${ }^{[13]}$ The smoothed values for the partial pressure of diatomic tellurium are given by,

$\log _{10} P_{2}(\mathrm{~atm})=-10,000 / T+6.346 ; \quad 1051-1230 \mathrm{~K}$.

Here and henceforth the partial pressure of diatomic tellurium will be written as $P_{2}$. At each measurement temperature, Eq 1 is used to calculate a partial pressure of diatomic tellurium. That of cadmium is taken as twice this. The standard Gibbs energy of formation for the reaction:

$\mathrm{Cd}(\mathrm{g})+\frac{1}{2} \mathrm{Te}_{2}(\mathrm{~g}) \rightarrow \mathrm{CdTe}(\mathrm{c})$

is given by:

$\Delta G_{\mathrm{f}}^{\mathrm{o}}=R T \ln \left(f_{\mathrm{Cd}} P_{\mathrm{Cd}} f_{2}^{1 / 2} P_{2}^{1 / 2}\right)$,

where $f_{j}$ is the fugacity coefficient of gaseous species $j$. These fugacity coefficients account for the nonideality of the vapor phase and can be expressed in terms of virial coefficients. It is assumed that the pressures involved are low enough that the second virial coefficient suffices. Then if the virial coefficients are written as $B_{J K}$ one has ${ }^{[14]}$ :

$$
\begin{aligned}
& \ln f_{\mathrm{Cd}}=P_{\mathrm{Cd}}\left(1+P_{2} / P_{\mathrm{T}}\right) B_{\mathrm{Cd}}+\left(P_{2}^{2} / P_{\mathrm{T}}\right)\left(2 B_{\mathrm{Cd}-\mathrm{Te}_{2}}-B_{\mathrm{Te}_{2}}\right) \\
& \ln f_{2}=P_{2}\left(1+P_{\mathrm{Cd}} / P_{\mathrm{T}}\right) B_{\mathrm{Te}_{2}}+\left(P_{\mathrm{Cd}}^{2} / P_{\mathrm{T}}\right)\left(2 B_{\mathrm{Cd}-\mathrm{Te}_{2}}-B_{\mathrm{Cd}}\right)
\end{aligned},
$$

where $P_{\mathrm{T}}$ is the total pressure. Studies of tellurium vapor ${ }^{[15]}$ have given its second virial coefficient as,

$B_{\mathrm{Te}_{2}}=-440.397 / T+0.26899 ; \quad T>900 \mathrm{~K}$.

The second virial coefficient for $\mathrm{Cd}(\mathrm{g})$ is calculated here. For the ground state we use a Leonard-Jones 6-12 potential 
determined from optical absorbance measurements ${ }^{[16]}$ of the $228.7 \mathrm{~nm}$ line at a number of temperatures and cadmium pressures. These gave an energy minimum of $0.0475 \mathrm{eV}$ and a separation at zero potential energy of $0.4295 \mathrm{~nm}$. A published $^{[17]}$ series solution was evaluated numerically to generate the virial coefficient as a function of temperature. The numerical result was fit with a standard deviation of $5 \mathrm{E}-05$ by the equation:

$B_{\mathrm{Cd}}=9.4649 / T^{1.25}-2662.6 / T^{2} ; 800-1436 \mathrm{~K}$.

Finally, the virial coefficient for the $\mathrm{Cd}-\mathrm{Te}_{2}$ interaction was assumed to be the average of those for $\mathrm{Cd}-\mathrm{Cd}$ and $\mathrm{Te}_{2}-\mathrm{Te}_{2}$,

$B_{\mathrm{Cd}-\mathrm{Te}_{2}}=(1 / 2)\left(B_{\mathrm{Cd}}+B_{\mathrm{Te}_{2}}\right)$.

Table 1 gives the temperature and value of the Gibbs energy according to $\mathrm{Eq} 3$. The fugacity coefficient correction is negative and reaches its largest absolute value of $27 \mathrm{~J} / \mathrm{mol}$ at $1245.2 \mathrm{~K}$.

The smoothed partial pressures of $\mathrm{Te}_{2}$ and $\mathrm{Cd}$ over Te-saturated CdTe as determined from optical absorbance measurements ${ }^{[18]}$ are given in Table 2 . The Gibbs energy of formation of $\mathrm{CdTe}$ from $\mathrm{Cd}(\mathrm{g})$ and $\mathrm{Te}_{2}$ as calculated with Eq 3 and that from the liquid elements (discussed later) are

Table 1 Gibbs energy of formation of $\mathrm{CdTe}(\mathrm{c})$ from gaseous and from condensed phase elements

\begin{tabular}{lcc}
\hline $\boldsymbol{T}, \mathbf{K}$ & $\begin{array}{c}-\Delta \boldsymbol{G}_{\mathbf{f}, \mathbf{2 9 8}}^{\mathbf{g}}(\mathbf{J} / \mathbf{m o l}) \text { from } \\
\text { gases, Eq 2 and 3 }\end{array}$ & $\begin{array}{c}-\Delta \boldsymbol{G}_{\mathbf{f}}^{\mathbf{0} 298}(\mathbf{J} / \mathbf{m o l}) \text { from solid } \\
\text { or liquid elements, Eq } \mathbf{1 5} \text { and 16 }\end{array}$ \\
\hline 1052.6 & 89289 & 81067 \\
1078.8 & 84376 & 79872 \\
1096.5 & 81049 & 79065 \\
1133.8 & 74008 & 77313 \\
1154.7 & 70091 & 76356 \\
1165.5 & 68071 & 75852 \\
1179.2 & 65472 & 75189 \\
1201.9 & 61229 & 74127 \\
1216.6 & 58436 & 73386 \\
1245.2 & 53075 & 72043 \\
\multicolumn{3}{c}{} \\
Calculated with partial pressure data from ref 13 \\
\hline
\end{tabular}

Table 2 Gibbs energy of formation of $\mathrm{CdTe}(\mathrm{c})$ from gaseous and from condensed phase elements

\begin{tabular}{lllcc}
\hline $\boldsymbol{T}, \mathbf{K}$ & $\begin{array}{c}\boldsymbol{P}_{\mathbf{2}}, \\
\mathbf{a t m}\end{array}$ & $\begin{array}{c}\boldsymbol{P}_{\mathbf{C d}}, \\
\mathbf{a t m}\end{array}$ & $\begin{array}{c}-\Delta \boldsymbol{G}_{\mathbf{f}, 298}^{\mathbf{0}}, \mathbf{J} / \mathbf{m o l} \\
\text { from gaseous } \\
\text { elements }\end{array}$ & $\begin{array}{c}-\Delta \boldsymbol{G}_{\mathbf{f}, 298}^{\mathbf{o}}, \mathbf{J} / \mathbf{m o l} \\
\text { from solid or } \\
\text { liquid elements }\end{array}$ \\
\hline 1337.0 & 0.042 & 0.190 & 36158 & 67957 \\
1351.0 & 0.023 & 0.310 & 34448 & 68204 \\
1360.0 & 0.012 & 0.480 & 33458 & 68472 \\
1366.1 & 0.0068 & 0.68 & 32933 & 68800
\end{tabular}

Partial pressure data from ref 18 also listed. The fugacity correction is negative, is essentially all due to tellurium, and is $210 \mathrm{~J} / \mathrm{mol}$ or less in magnitude.

The first three columns of Table 3 give the temperature and partial pressure of $\mathrm{Te}_{2}$ obtained from Knudsen cell measurements by Goldfinger and Jeunehomme. ${ }^{[19]}$ The Gibbs energies are from an equation given in the caption of their Fig. 6 and are calculated for each temperature in that figure, which is a plot of $\log K$ versus $1000 / T$. The partial pressure of $\mathrm{Te}_{2}$ is calculated from this Gibbs energy assuming an effusion steady state in which the flux of $\mathrm{Te}_{2}$ out from the Knudsen cell in moles/sec is one-half that of $\mathrm{Cd}$. Then inside the cell the pressures are related by,

$P_{\mathrm{Cd}}=2\left(M_{\mathrm{Cd}} / M_{\mathrm{Te}_{2}}\right)^{1 / 2} P_{2}=1.327 P_{2}$.

The quantities within the square root are the atomic weight of $\mathrm{Cd}$ and molecular weight of diatomic tellurium. The Gibbs energy was recalculated with these partial pressures according to $\mathrm{Eq} 3$. The correction for a non ideal vapor was $<1 \mathrm{~J} / \mathrm{mol}$.

The corrected Gibbs energies from the above three sources are shown in Fig. 1 and can be seen to fall close to the same straight line. A least squares fit to the data gives a standard deviation is $303 \mathrm{~J} / \mathrm{mol}$ and is represented by:

$\Delta G_{\mathrm{f}}^{\mathrm{o}}(\mathrm{J} / \mathrm{mol})=-284730+185.80 T$.

The diamonds at high temperature are for Te-saturated $\mathrm{CdTe}^{[20]}$ and were not included in the least squares fit. For the open diamonds the partial pressure was calculated from the $\mathrm{Cd}$ peak at $325.7 \mathrm{~nm}$ while for the closed diamonds it was calculated from the absorbance at $240.0 \mathrm{~nm}$ in the far wing of the strongly absorbing $228.7 \mathrm{~nm}$ peak. The fugacity correction ranges from -77 to $-200 \mathrm{~J} / \mathrm{mol}$ at $1348 \mathrm{~K}$. For these points the partial pressure of diatomic tellurium is decreasing from 0.131 atm at $1238 \mathrm{~K}$ to $0.0248 \mathrm{~atm}$ at

Table 3 Partial pressures from Knudsen cell measurements of reference 19 and Gibbs energy of formation

\begin{tabular}{|c|c|c|c|c|}
\hline$T, \mathbf{K}$ & $\begin{array}{c}P_{2}, \\
\text { atm }\end{array}$ & $\begin{array}{c}P_{\mathrm{Cd}}, \\
\text { atm }\end{array}$ & $\begin{array}{c}-\Delta G_{\mathrm{f}, 298}^{\mathbf{o}}, \mathrm{J} / \mathrm{mol} \\
\text { from gaseous } \\
\text { elements }\end{array}$ & $\begin{array}{c}-\Delta G_{\mathrm{f}, 298}^{\mathbf{0}}, \mathrm{J} / \mathrm{mol} \\
\text { from solid or } \\
\text { liquid elements }\end{array}$ \\
\hline 733.1 & $3.84 \mathrm{E}-7$ & $5.09 \mathrm{E}-7$ & 140610 & 92192 \\
\hline 781.9 & $5.32 \mathrm{E}-7$ & $7.06 \mathrm{E}-7$ & 139030 & 91895 \\
\hline 794.8 & $8.50 \mathrm{E}-7$ & $1.13 \mathrm{E}-6$ & 136680 & 91438 \\
\hline 813.7 & $1.64 \mathrm{E}-6$ & $2.17 \mathrm{E}-6$ & 133280 & 90776 \\
\hline 829.1 & $2.74 \mathrm{E}-6$ & $3.64 \mathrm{E}-6$ & 130460 & 90187 \\
\hline 845.2 & $4.59 \mathrm{E}-6$ & $6.09 \mathrm{E}-6$ & 127570 & 89629 \\
\hline 860.3 & $7.33 \mathrm{E}-6$ & $9.73 \mathrm{E}-6$ & 124830 & 89670 \\
\hline 877.7 & $1.23 \mathrm{E}-5$ & $1.63 \mathrm{E}-5$ & 121700 & 88459 \\
\hline 895.6 & $2.05 \mathrm{E}-5$ & $2.73 \mathrm{E}-5$ & 118440 & 87785 \\
\hline 905.8 & $2.72 \mathrm{E}-5$ & $3.61 \mathrm{E}-5$ & 116620 & 87423 \\
\hline 916.2 & $3.60 \mathrm{E}-5$ & $4.78 \mathrm{E}-5$ & 114750 & 87055 \\
\hline 926.8 & $4.77 \mathrm{E}-5$ & $6.33 \mathrm{E}-5$ & 112820 & 86656 \\
\hline 950.6 & $8.78 \mathrm{E}-5$ & $1.16 \mathrm{E}-4$ & 108490 & 85727 \\
\hline 960.1 & $1.11 \mathrm{E}-4$ & $1.47 \mathrm{E}-4$ & 106790 & 85375 \\
\hline 979.7 & $1.77 \mathrm{E}-4$ & $2.35 \mathrm{E}-4$ & 103240 & 84630 \\
\hline 1006.5 & $3.26 \mathrm{E}-4$ & $4.32 \mathrm{E}-4$ & 98412 & 83623 \\
\hline
\end{tabular}




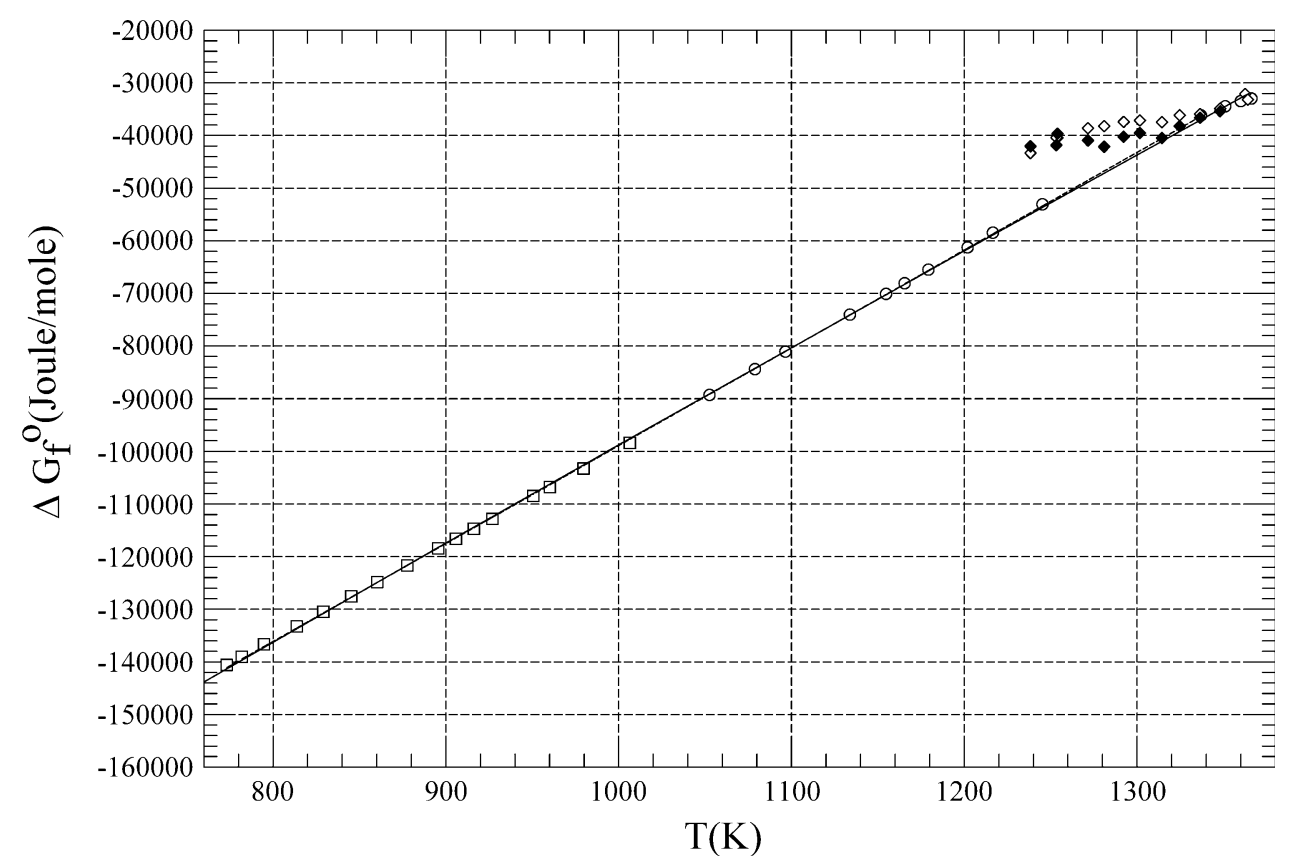

Fig. 1 Gibbs energy of formation of $\mathrm{CdTe}(\mathrm{c})$ from gaseous cadmium and diatomic tellurium each at 1 atm. Squares; ref 19, Knudsen cell. circles; ref 13, optical absorption. Circles at and above $1245 \mathrm{~K}$, ref 18, vapor over Te-saturated CdTe (c). Dashed line from second law analysis, Eq 9. Solid line from third law analysis with $\Delta H_{\mathrm{f}, 298}^{\mathrm{o}}=-293262 \mathrm{~J} / \mathrm{mol}$ and $S_{298}^{\mathrm{o}}(\mathrm{CdTe}(\mathrm{c}))=96.367$ or $\Delta S_{\mathrm{f}, 298}^{\mathrm{o}}=$ $-200.593 \mathrm{~J} / \mathrm{mol} \mathrm{K}$

$1348 \mathrm{~K}$. With increasing temperature the points approach and then coincide with the least squares line. The discrepancy at the lowest temperatures is most likely due to the fact that the absorbance at the $\mathrm{Cd}$ peaks has not been corrected for pressure broadening by $\mathrm{Te}_{2}$. It would appear that this effect is negligible from about $1330 \mathrm{~K}$ upward. These data have not been included in the analysis except as an indication that the pressure broadening is negligible for the four circles from Table 2 at the highest temperatures.

\subsection{Third Law Analysis}

At equilibrium between $\mathrm{CdTe}(\mathrm{c})$ and the vapor phase, the chemical potential of cadmium must be the same in both phases, as must be that of tellurium. Moreover, the chemical potential of tellurium is equal to one-half that of the gaseous, diatomic tellurium molecule. Adding the two equations for the chemical potentials and applying standard thermodynamic formulae one arrives at the equation,

$$
\begin{aligned}
\Delta G_{\mathrm{f}}^{\mathrm{o}}= & \Delta H_{\mathrm{f}, 298}^{\mathrm{o}}-T S_{298}^{\mathrm{o}}+\left(H_{\mathrm{T}}^{\mathrm{o}}-H_{298}^{\mathrm{o}}\right)_{\mathrm{CdTe}} \\
& -T\left(S_{\mathrm{T}}^{\mathrm{o}}-S_{298}^{\mathrm{o}}\right)_{\mathrm{CdTe}}-\left(H_{\mathrm{T}}^{\mathrm{o}}-H_{298}^{\mathrm{o}}\right)_{\mathrm{Cd}(\mathrm{g})} \\
& +T S_{\mathrm{T}, \mathrm{Cd}(\mathrm{g})}^{\mathrm{o}}-(1 / 2)\left(H_{\mathrm{T}}^{\mathrm{o}}-H_{298}^{\mathrm{o}}\right)_{\mathrm{Te}_{2}(\mathrm{~g})} \\
& +(1 / 2) T S_{\mathrm{T}, \mathrm{Te}_{2}(\mathrm{~g})}^{\mathrm{o}}
\end{aligned}
$$

where $\Delta G_{\mathrm{f}}^{\mathrm{o}}$ is the standard Gibbs energy of formation of $\mathrm{CdTe}(\mathrm{c})$ from the gases as given by Eq 3. Our choice of the standard entropy at $298 \mathrm{~K}$ for $\mathrm{CdTe}(\mathrm{c})$ as a parameter, rather than the standard entropy of the reaction, is arbitrary and of no fundamental significance. If the heat capacity of $\mathrm{CdTe}(\mathrm{c})$, the chemical potentials of $\mathrm{Cd}(\mathrm{g})$ and $\mathrm{Te}_{2}(\mathrm{~g})$, and $\Delta H_{\mathrm{f}, 298}^{\mathrm{o}}$ and $S_{298}^{\mathrm{o}}$ are known, then at each temperature one can calculate a value for the right side of $\mathrm{Eq} 10$ for comparison with the experimental value of the Gibbs energy. Here we treat the enthalpy of formation and the entropy of $\mathrm{CdTe}(\mathrm{c})$ at $298 \mathrm{~K}$ as variables. Although values exist for them in the literature we expect that small adjustments will be necessary to minimize the standard deviation between the values of the standard Gibbs energy calculated with $\mathrm{Eq} 10$ and those observed. Before discussing this minimization we indicate the values used for the other quantities in the right side of $\mathrm{Eq} 10$.

The sources of the quantities in Eq 10 that are assumed to be known are as follows. With a value of $20.786 \mathrm{~J} / \mathrm{mol} \mathrm{K}$ for the constant pressure heat capacity ${ }^{[21]}$ of $\mathrm{Cd}(\mathrm{g})$ above $298.15 \mathrm{~K}$ and a standard entropy at $298.15 \mathrm{~K}$ of $167.63 \mathrm{~J} /$ mol $\mathrm{K}$ one arrives at the results:

$$
\begin{aligned}
\left(\Delta H_{\mathrm{T}}^{\mathrm{o}}-\Delta H_{298}^{\mathrm{o}}\right) & =20.7861(T-298.15) \\
S_{\mathrm{T}, \mathrm{Cd}(\mathrm{g})}^{\mathrm{o}} & =49.201+20.7861 \operatorname{Ln}(T)
\end{aligned}
$$

Similarly, for $T$ above $298 \mathrm{~K}$ the thermodynamic properties of $\mathrm{Te}_{2}(\mathrm{~g}, 1 \mathrm{~atm})$ were calculated by Mills ${ }^{[7]}$ from spectroscopic constants. These properties can be simply but accurately given between 400 and $1400 \mathrm{~K}$ using the constant pressure heat capacity:

$$
C_{p}(\mathrm{~J} / \mathrm{mol} \mathrm{K})=29.070+0.02645 T-1.1484\left(10^{-5}\right) T^{2} .
$$


With this result and a standard entropy at $298.15 \mathrm{~K}$ of $258.66 \mathrm{~J} / \mathrm{mol} \mathrm{K}$, one has,

$$
\begin{aligned}
\left(H_{\mathrm{T}}^{\mathrm{o}}-H_{\mathrm{T}}^{\mathrm{o}}\right)_{\mathrm{Te}_{2}(\mathrm{~g})}= & 29.070(T-298.15) \\
& +0.013228\left(T^{2}-298.15^{2}\right) \\
& -3.828\left(10^{-6}\right)\left(T^{3}-298.15^{3}\right) \quad(\mathrm{Eq} 13) \\
S_{\mathrm{T}, \mathrm{Te}_{2}(\mathrm{~g})}^{\mathrm{o}}= & 85.645+.026456 T-5.742\left(10^{-6}\right) T^{2} \\
& +29.070 \mathrm{Ln}(T)
\end{aligned}
$$

Because we have found that constant pressure heat capacities for $\mathrm{CdTe}(\mathrm{c})$ given by Yamaguchi et al. ${ }^{[2]}$. and by Pavlova et al. ${ }^{[3]}$ give close to the same fits to the data used here we use a heat capacity that is the average of these two:

$C_{p}=48.740+.008505 T-1.171\left(10^{5}\right) / T^{2}$.

The heat capacities given by Pavlova, by Yamaguchi, and in our study ${ }^{[6]}$ of the Cd-Te system are all $50 \pm 0.5 \mathrm{~J} / \mathrm{mol} \mathrm{K}$ at $298 \mathrm{~K}$. However, they differ significantly at the $1365 \mathrm{~K}$ melting point where they are, respectively, 58.7, 62.0, and 70. We also note that the heat contents calculated with the heat capacity given by Yamaguchi et al. are larger than those calculated with that given by Pavlova et al., but by $<1 \mathrm{~J} / \mathrm{mol}$ between 298 and $800 \mathrm{~K}$ and by only $1 \mathrm{~kJ} / \mathrm{mol}$ at $1365 \mathrm{~K}$.

The linear theory of adjustment ${ }^{[22]}$ was used to obtain the values at $298 \mathrm{~K}$ for the standard enthalpy of formation of and the entropy for $\mathrm{CdTe}(\mathrm{c})$ which minimize the standard deviation between calculated and observed values for the Gibbs energy. The $95 \%$ confidence levels in these quantities were also obtained. Then the Simplex trial and error method of Nelder and Mead ${ }^{[23]}$ was used to calculate the standard deviation and the value for the enthalpy for fixed values of the entropy in the neighbor hood of the best fit.. The best fit to the left side of Eq 10 is attained with $\Delta H_{298}^{\mathrm{o}}=$ $-294,008 \mathrm{~J} / \mathrm{mol}, S_{298}^{\mathrm{o}}=95.64 \mathrm{~J} / \mathrm{mol} \mathrm{K}$, and a standard deviation of $410 \mathrm{~J} / \mathrm{mol}$. However, as is shown in Fig. 2, there is a wide range of enthalpy and entropy values falling along a straight line which give almost equally good fits. The standard deviation rises rapidly with small departures from this line. As has been pointed out, ${ }^{[24]}$ this is a feature of linear least squares fits to a set of data made over a temperature range small compared to the average temperature of the measurements themselves. Moreover, if the enthalpy is expressed as a linear function of the entropy, then the slope (coefficient of the entropy) is the reciprocal of the average value of $1 / T$ of the measurements, 1007.9 in this case. This best fit line is useful in attaining consistency with the quantities for the formation from the condensed phase elements since it turns out to be necessary to move away from the very best fit. It is also useful in graphically demonstrating that the uncertainties in the enthalpy and entropy are strongly correlated. Along this best fit line the literature value of $-293,000 \mathrm{~J} / \mathrm{mol}$ for the enthalpy change corresponds to a standard entropy at 298 for $\mathrm{CdTe}$ (c) of 96.6 and $\sigma=440$, just above the minimum value. Similarly, the literature value of 95 for the entropy corresponds to an enthalpy of formation of $-294,600$ and a standard deviation of 420 , again just above the minimum attained. However, the paired literature values of $-293,000$ and 95 are off the best fit line and correspond to $\sigma=1702$. This is about four

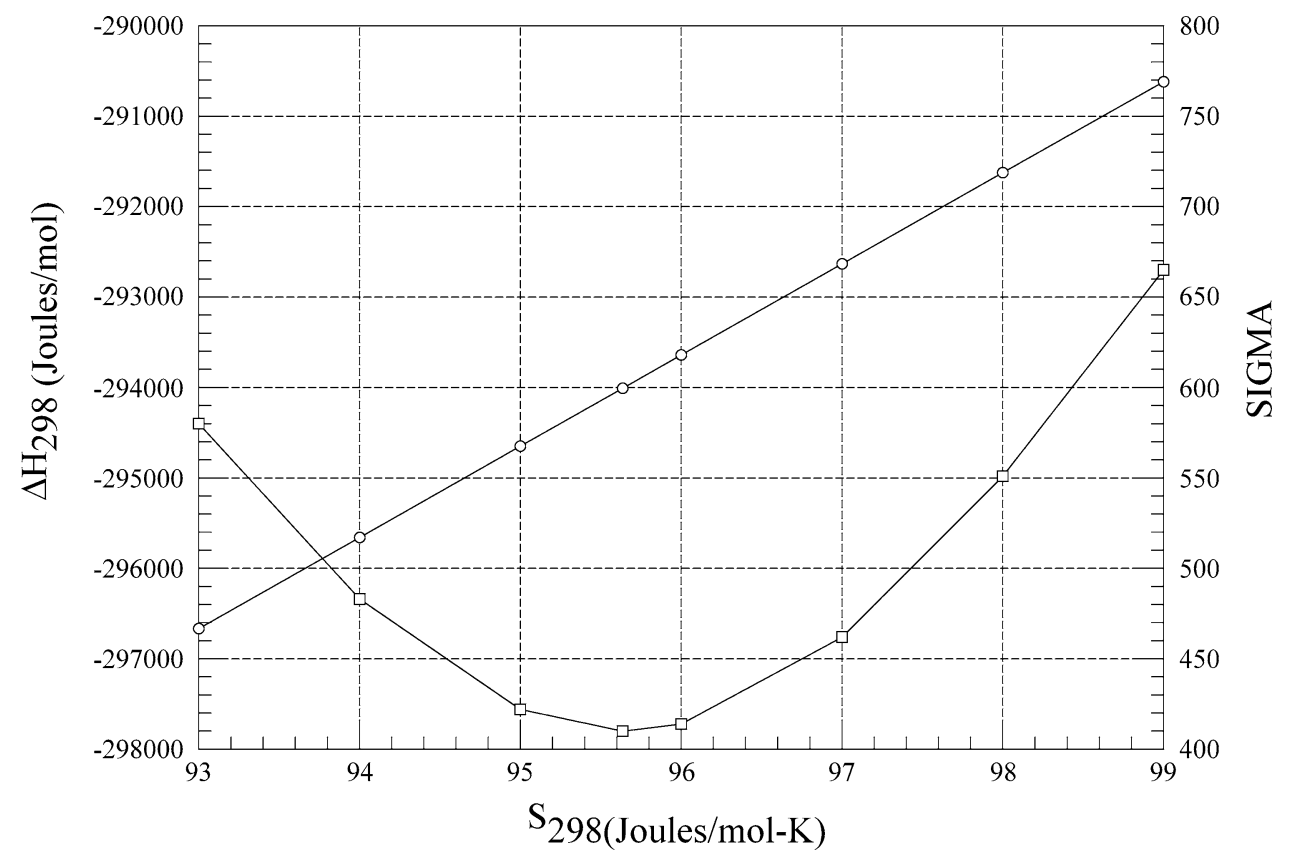

Fig. 2 The parabola-like curve shows the best fit between the observed Gibbs energies of formation in Fig. 1 and third law values as a function of the standard entropy of $\mathrm{CdTe}(\mathrm{c})$ at $298 \mathrm{~K}$. The best fit or standard deviation between observed and calculated values is given by the right vertical axis. The straight line shows corresponding values of the standard enthalpy of formation and the standard entropy of $\mathrm{CdTe}(\mathrm{c})$ at $298 \mathrm{~K}$ that give a best fit for a fixed value of the entropy 
times the minimum value. It is apparent that a small adjustment is required in these parameters. Further discussion is delayed until the Gibbs energy of formation from the condensed phase elements is analyzed.

\section{Formation of $\mathrm{CdTe}(\mathrm{c})$ from Its Condensed Phase Elements}

\subsection{Calculation of the Gibbs Energy of Formation from Data}

For the reaction,

$\mathrm{Cd}(\mathrm{c}, 1)+\mathrm{Te}(\mathrm{c}, 1) \rightarrow \mathrm{CdTe}(\mathrm{c})$,

the Gibbs energy of formation is given by,

$\Delta G_{\mathrm{f}}^{\mathrm{o}}=R T \ln \left(P_{\mathrm{Cd}} f_{\mathrm{Cd}} / P_{\mathrm{Cd}}^{\mathrm{o}} f_{\mathrm{Cd}}^{\mathrm{o}}\right)+(1 / 2) R T \ln \left(P_{2} f_{2} / P_{2}^{\mathrm{o}} f_{2}^{\mathrm{o}}\right)$,

where the superscript circle indicates a partial pressure or fugacity in the vapor over the pure element. For cadmium, the necessary properties are taken from Hultgren et al. ${ }^{[21]}$ and have also been adopted by SGTE. ${ }^{[25]}$ They are:

$C_{p}=22.30+.01213 T ; 298<T<594.2 ;$ m.pt.594.2 K;

Enthalpy of fusion $=6192 \mathrm{~J} / \mathrm{mol}$

$C_{p}=29.71 ; T>594.2 \mathrm{~K}$

$\mathrm{Cd}(\mathrm{c}) ; S_{298}^{\mathrm{o}}=51.80 \mathrm{~J} / \mathrm{molK} \quad \mathrm{Cd}(\mathrm{g}) ; S_{298}^{\mathrm{o}}=167.63$

$\mathrm{Cd}(\mathrm{c}) \rightarrow \mathrm{Cd}(\mathrm{g}) \Delta H_{\mathrm{f}, 298}^{\mathrm{o}}=111,960 \mathrm{~J} / \mathrm{mol}$

$\log _{10} P_{\mathrm{Cd}}(\mathrm{atm})=5.119-5317 / T ; T>594.2 \mathrm{~K}$

The corresponding quantities for tellurium are taken from our third law analysis ${ }^{[9]}$ of the crystal-liquid-vapor equilibrium. As mentioned earlier, the heat capacity above the melting point is quite different from that given by Mills ${ }^{[7]}$ and used in previous studies. It is close to that adopted by Davydov et al. ${ }^{[11]}$ The enthalpy and entropy of $\mathrm{Te}(1)$ calculated with our heat capacity and that of Davydov et al. differ by $<0.5 \%$ between 722.65 and $1365 \mathrm{~K}$. However, our vapor pressures are $7-20 \%$ higher than those adopted by Davydov et al. and closer to the experimental values. The necessary thermodynamic data for tellurium are:

m. pt. $=722.65 \mathrm{~K}$; heat of fusion $=17,489 \mathrm{~J} / \mathrm{mol}$

$$
\begin{aligned}
& C_{p}= 24.610+0.003217 T+1.678\left(10^{-6}\right) T^{2} ; \\
& 298<T<722.65 \\
& C_{p}= 131.7-0.1185 T ; \quad 722.65<T<833 K \\
& C_{p}=32.94 ; \quad T>833 \mathrm{~K} \\
& \mathrm{Te}(\mathrm{c}) ; S_{298}^{\mathrm{o}}=49.1 \mathrm{~J} / \mathrm{mol} \mathrm{K} \quad \mathrm{Te}_{2}(\mathrm{~g}) ; \quad S_{298}^{\mathrm{o}}=258.66 \\
& \mathrm{Te}(\mathrm{c}) \rightarrow \frac{1}{2} \operatorname{Te}_{2}(\mathrm{~g}) ; \Delta H_{\mathrm{f}, 298}^{\mathrm{o}}=81,031 \mathrm{~J} / \mathrm{mol}
\end{aligned}
$$

We originally gave ${ }^{[9]}$ four equations for the vapor pressure between 722.65 and $1434 \mathrm{~K}$. We now find that these can be approximated to better than two percent by the single equation:

$\log _{10} P(\operatorname{atm})=4.3985-5267.68 / T-368192.2 / T^{2} ;$

$$
722.65<T<1434 \mathrm{~K}
$$

In this temperature range, the saturated vapor is $99 \%$ or better $\mathrm{Te}_{2}(\mathrm{~g}){ }^{[7]}$

With the above input data the Gibbs energy of formation from the gaseous elements in Table 1-3 were converted to Gibbs energies of formation from the condensed phase elements following the reaction in Eq 15. The results are shown in the last column of Table 1-3. For the entries shown in Table 1, the correction for vapor phase nonideality are all positive and range from $81 \mathrm{~J} / \mathrm{mol}$ at $1052 \mathrm{~K}, 73$ of which arise from the tellurium correction, and $375 \mathrm{~J} / \mathrm{mol}$ at $1245 \mathrm{~K}$, 343 of are from the tellurium term. In Table 2, the corrections are all about $550 \mathrm{~J} / \mathrm{mol}$ with the tellurium contribution being about 500. The corrections for Table 3 are all positive and range from $47 \mathrm{~J} / \mathrm{mol}$ at $1006 \mathrm{~K}, 43$ of which are from the tellurium term, to $0.2 \mathrm{~J} / \mathrm{mol}$ at $733 \mathrm{~K}$. The corrected Gibbs energies are shown in Fig. 3 as symbols.

Also shown in Fig. 3 are data from emf measurements. There are four line segments below $722.6 \mathrm{~K}$ terminated by symbols. ${ }^{[25-28]}$ The symbols indicate the temperature limits of the measurements. The measurements of Shamsuddin and Nasar ${ }^{[29]}$ are shown as solid triangles between 640 and $845 \mathrm{~K}$. They were extracted by us from a scaled plot of emf versus $T$. The cell electrodes were described as $\mathrm{Cd}(1)$ and $\mathrm{CdTe}(\mathrm{c})+\mathrm{Te}(\mathrm{c}, \mathrm{l})$. However, the $\mathrm{CdTe}(\mathrm{c})-\mathrm{Te}(\mathrm{s})$ eutectic is close to $722.6 \mathrm{~K}$ so the anode description cannot be correct above about $722.6 \mathrm{~K}$. Taking the authors description of the $\mathrm{CdTe}$ (c) electrode as containing $10 \% \mathrm{Te}$ to have been calculated with $\mathrm{CdTe}$ and $\mathrm{Te}$ as components, then this electrode is about 52 at.\% $\mathrm{Te}$ using $\mathrm{Cd}$ and $\mathrm{Te}$ as components. This composition falls in the two phase CdTe and Te rich liquid region up to over $1000 \mathrm{~K}$. The Gibbs energy measured is then the difference in the chemical potential of $\mathrm{Cd}$ in $\mathrm{CdTe}$ (c) as Te rich as possible and that in pure $\mathrm{Cd}(\mathrm{l})$. To obtain the Gibbs energy of formation of CdTe (c) from its elements one must add a correction term, $\frac{1}{2} R T \ln P_{2} / P_{2}^{\mathrm{o}}$, where $P_{2}$ is the partial pressure of diatomic tellurium over the "Te-saturated" $\mathrm{CdTe}(\mathrm{c})$ and $P_{2}^{\mathrm{o}}$ is that over pure Te(l). The former partial pressure has been obtained from optical absorbance measurements ${ }^{[18]}$ down to $934 \mathrm{~K}$ where it is $0.017 \mathrm{~atm}$ compared to 0.021 for pure $\mathrm{Te}(1)$. Thus, the correction term is $-240 \mathrm{~J} /$ mol at $934 \mathrm{~K}$ and is expected to approach zero as the temperature is lowered to $722.6 \mathrm{~K}$ and the liquidus line approaches 100 at.\% Te. We ignore this small correction here. It should be noted, as seen in Fig. 3, that the Gibbs energies from Shamsuddin and Nasar are more negative than those of all the others by about $2000 \mathrm{~J} / \mathrm{mole}$ near $800 \mathrm{~K}$ and about $1000-2000 \mathrm{~J} / \mathrm{mol}$ below $722.6 \mathrm{~K}$.

A linear least squares fit to the data in Fig. 3 above $722.6 \mathrm{~K}$ and excluding that of Shamsuddin and Nasar gives,

$\Delta G_{\mathrm{f}}^{\mathrm{o}}(\mathrm{J} / \mathrm{mol})=-126372+43.2897 T ; \quad$ Std. dev. $=415$.

(Eq 20)

This equation is plotted as the dashed line in Fig. 3. 


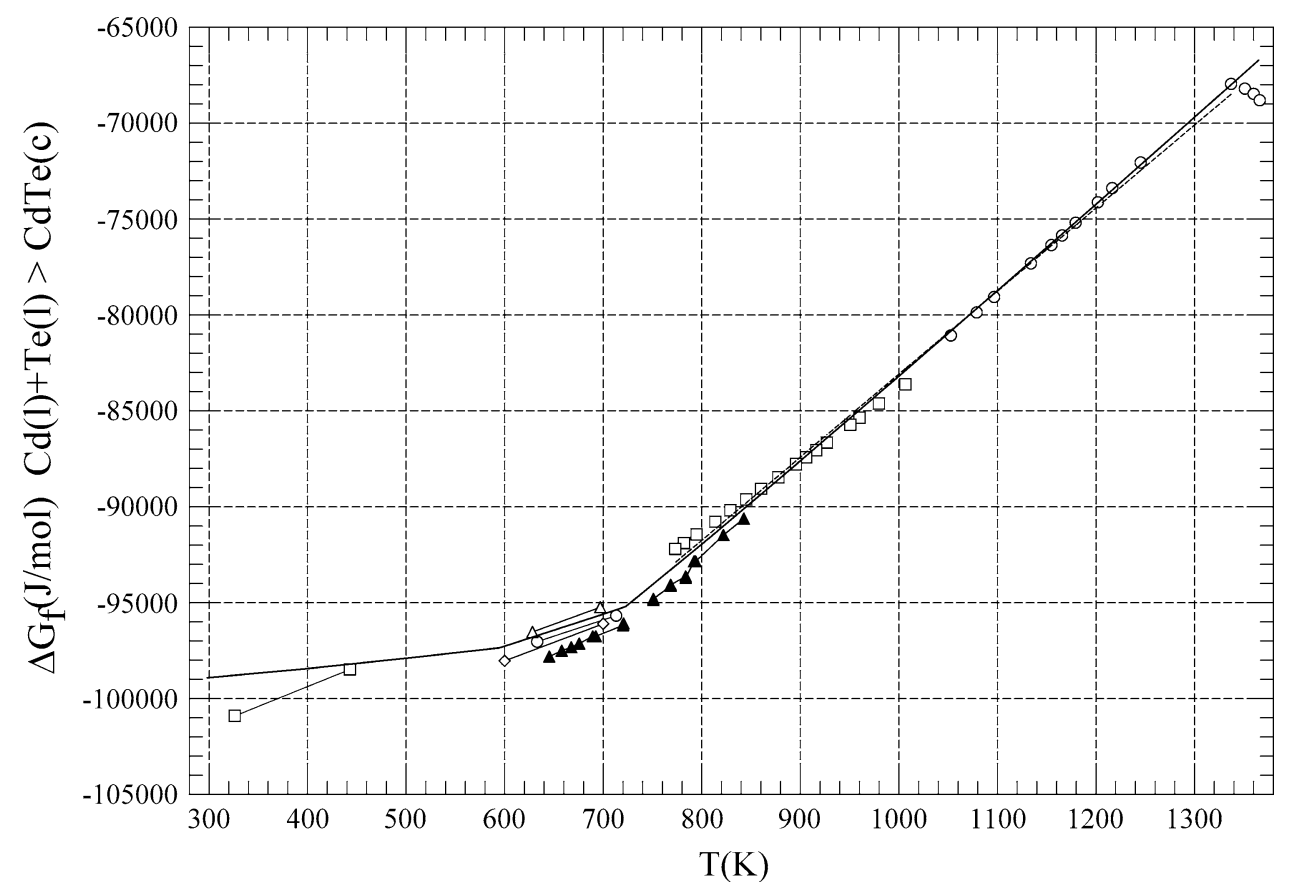

Fig. 3 Standard Gibbs energy of formation of $\mathrm{CdTe}(\mathrm{c})$ from its solid or liquid elements as a function of temperature. Squares and circles above $722.6 \mathrm{~K}$ as in Fig. 1. Line segments terminated by symbols and below $722.6 \mathrm{~K}$ are from emf measurements. Squares: ref 27, circles: ref 25, diamonds: ref 28, triangles: ref 26, solid triangles: ref 29; Dashed line is a second law analysis and is given by Eq 20. Solid line is a third law analysis with $\Delta H_{\mathrm{f}, 298}^{\mathrm{o}}=-100270 \mathrm{~J} / \mathrm{mol}$ and $\Delta S_{\mathrm{f}, 298}^{\mathrm{o}}=-4.53335 \mathrm{~J} / \mathrm{mol} \mathrm{K}$

\subsection{Third Law Analysis}

The Gibbs energies for the formation of $\mathrm{CdTe}(\mathrm{c})$ from its condensed phase elements can be analyzed using an analogue of Eq 10. However, in contrast to Eq 10 we use the standard entropy of formation for the reaction given by Eq 15 as an adjustable parameter rather than the standard entropy of $\mathrm{CdTe}(\mathrm{c})$. The equation is:

$$
\begin{aligned}
& \Delta G_{\mathrm{f}}^{\mathrm{o}}=\Delta H_{\mathrm{f}, 298}^{\mathrm{o}}-T \Delta S_{\mathrm{f}, 298}^{\mathrm{o}}+\Delta\left(H_{\mathrm{T}}^{\mathrm{o}}-H_{298}^{\mathrm{o}}\right) \\
& -T \Delta\left(S_{\mathrm{T}}^{\mathrm{o}}-S_{298}^{\mathrm{o}}\right) \\
& \text { where } \Delta\left(H_{\mathrm{T}}^{\mathrm{o}}-H_{298}^{\mathrm{o}}\right)=\left(H_{\mathrm{T}}^{\mathrm{o}}-H_{298}^{\mathrm{o}}\right)_{\mathrm{CdTe}(\mathrm{c})}-\left(H_{\mathrm{T}}^{\mathrm{o}}-H_{298}^{\mathrm{o}}\right)_{\mathrm{Cd}} \\
& -(1 / 2)\left(H_{\mathrm{T}}^{\mathrm{o}}-H_{298}^{\mathrm{o}}\right)_{T_{2}}
\end{aligned}
$$

and where an equation analogous to the second of Eq 21 holds for the entropy. Knowing the heat capacities for $\mathrm{CdTe}(\mathrm{c})$ and its elements and the standard enthalpy and entropy of formation at $298 \mathrm{~K}$, the right side of the equation can be calculated. Analogous to the discussion for the formation of $\mathrm{CdTe}$ (c) from the gases, the standard enthalpy and entropy of formation are considered as variable parameters. It is expected that these must be varied slightly from their literature values to achieve a compromise of a good fit to the observed Gibbs energies and consistency with the results for the formation from the gases.

The values of $\Delta H_{\mathrm{f}, 298}^{\mathrm{o}}$ and $\Delta S_{\mathrm{f}, 298}^{\mathrm{o}}$ were determined which gave the smallest standard deviation between the observed values for $\Delta G_{\mathrm{f}}^{\mathrm{o}}$ and those calculated with the right side of
Eq 21. Then, the best fit was determined for fixed values of $\Delta S_{\mathrm{f}, 298}^{\mathrm{o}}$. The results are shown in Fig. 4. Because the data from Shamsuddin and Nasar are more negative than all the other data, two determinations were made, one was including their data, the second omitting it. Excluding their data, the best fit to 33 points has a standard deviation of $416 \mathrm{~J} / \mathrm{mol}$ with a standard enthalpy of formation of $-100001 \pm 726 \mathrm{~J} / \mathrm{mol}$ and standard entropy of $-4.245 \pm$ $0.75 \mathrm{~J} / \mathrm{mol} \mathrm{K}$, both at $298.15 \mathrm{~K}$. Again, as shown in Fig. 4 there is a wide range of enthalpy-entropy values that fall along a straight line along which the standard deviation between experimental and calculated Gibbs energies of formation changes slowly. If one fixes the standard entropy at the literature value of $-5.9 \mathrm{~J} / \mathrm{mol} \mathrm{K}$ then the corresponding enthalpy is $-101645 \mathrm{~J} / \mathrm{mol}$ with a fit of $528 \mathrm{~J} / \mathrm{mol}$. On the other hand if one fixes the standard enthalpy at the literature value of $-100663 \mathrm{~J} / \mathrm{mol}$, then the corresponding entropy is -4.924 with a slightly better fit of $424 \mathrm{~J} / \mathrm{mol}$. If both the standard enthalpy and entropy are fixed at the literature values of -100663 and -5.9 , then the standard deviation of the fit more than doubles to $1148 \mathrm{~J} / \mathrm{mol}$.

\section{Discussion}

If one denotes Eq 2 for the formation of CdTe from $\mathrm{Cd}(\mathrm{g})$ and $\mathrm{Te}_{2}(\mathrm{~g})$ as II and $\mathrm{Eq} 15$ for its formation from the condensed phase elements as I, then the corresponding 
enthalpies and entropies of formation are related by the equations,

$$
\begin{aligned}
\Delta H_{\mathrm{f}, 298}^{\mathrm{o}}(\mathrm{II}) & =\Delta H_{\mathrm{f}, 298}^{\mathrm{o}}(\mathrm{I})-192991 \\
\Delta S_{\mathrm{f}, 298}^{\mathrm{o}}(\mathrm{II}) & =\Delta S_{\mathrm{f}, 298}^{\mathrm{o}}(\mathrm{I})-196.06 \\
S_{298}^{\mathrm{o}}(\mathrm{CdTe}) & =\Delta S_{\mathrm{f}, 298}^{\mathrm{o}}(\mathrm{II})+296.96
\end{aligned}
$$

Equations 17 and 18 for the thermodynamic properties of pure cadmium and tellurium have been used in $\mathrm{Eq} 22$. Furthermore, since the standard deviation of the fit to the experimental Gibbs energies of formation increases rapidly as the enthalpy-entropy point is moved away from the best fit line shown in Fig. 2 and 4, acceptable values for these enthalpies and entropies must lie on these lines. The lines are given by,

$$
\begin{gathered}
\Delta H_{\mathrm{f}, 298}^{\mathrm{o}}(\mathrm{I})=938.098 * \Delta S_{\mathrm{f}, 298}^{\mathrm{o}}(\mathrm{I})-96017.8 \\
\Delta H_{\mathrm{f}, 298}^{\mathrm{o}}(\mathrm{II})=1007.98 * S_{298}^{\mathrm{o}}(\mathrm{CdTe})-390398
\end{gathered}
$$

The solution to Eq 22 and 23 are enthalpies and entropies that give the best fits to the experimental Gibbs energies of formation which are consistent with the thermodynamic data assumed for pure cadmium and tellurium and the assumed heat capacity of CdTe. They are,

$$
\begin{array}{llll}
\Delta H_{\mathrm{f}, 298}^{\mathrm{o}}(\mathrm{J} / \mathrm{mol}) & \Delta S_{\mathrm{f}, 298}^{\mathrm{o}}(\mathrm{J} / \mathrm{mol} \mathrm{K}) & S_{298}^{\mathrm{o}}(\mathrm{CdTe}) & \sigma(\mathrm{J}) \\
-100270 & -4.53335 & 96.367 & 420 \\
-293262 & -200.593 & 96.367 & 430
\end{array}
$$

Here $\sigma$ is the standard deviation between experimental and calculated standard Gibbs energies of formation and is close to the minimum attained in each case. The Gibbs energies obtained with the above parameters are shown as the solid lines in Fig. 1 and 3. They are in good agreement with the experimental points and the dashed lines representing second law fits. Analytical expressions for the Gibbs energy of formation are listed in Table 4. It should be noted that determinations for $\Delta H_{\mathrm{f}, 298}^{\mathrm{o}}(\mathrm{I})$ by metal

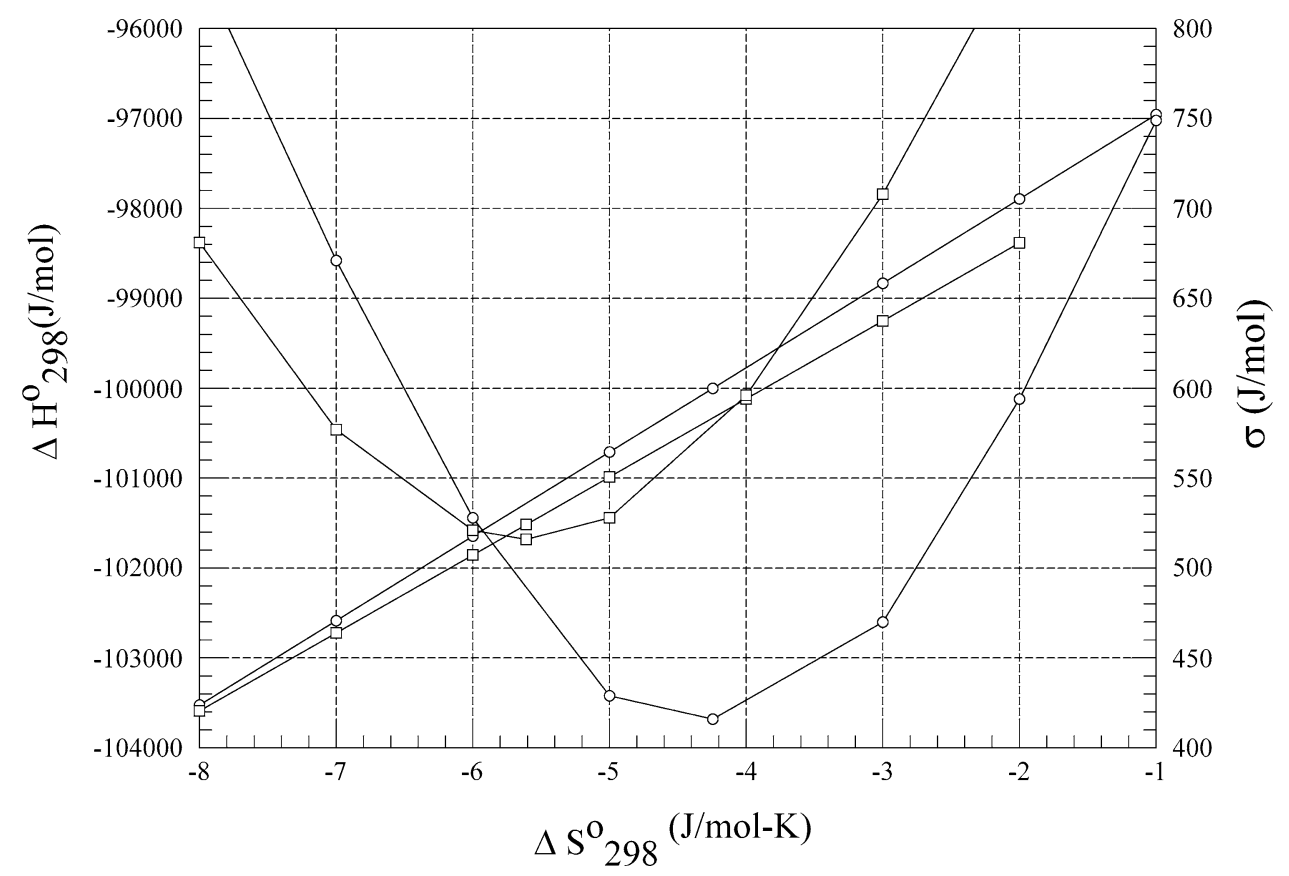

Fig. 4 Measure of fit for the standard Gibbs energy of formation of $\mathrm{CdTe}(\mathrm{c})$ from its condensed phase elements as a function of the standard entropy of formation at $298 \mathrm{~K}$. Curves are analogous to those in Fig. 2. The curves shown with circles are from analyses using the data shown in Fig. 3 but excluding the data of ref 29. Those shown with squares include that data

Table 4 Analytical formulae for the Gibbs energy of formation of $\mathrm{CdTe}(\mathrm{c})$ from its condensed phase elements and, in the last row, from $\mathrm{Cd}(\mathrm{g})$ and $1 / 2 \mathrm{Te}_{2}(\mathrm{~g}) \Delta G_{\mathrm{f}}^{\mathbf{0}}(\mathrm{J} / \mathrm{mol})=A+B T+C T^{2}+D T^{3}+E T \ln (T)+F / T$

\begin{tabular}{lccccr}
\hline Temp. range, K & $\boldsymbol{A}$ & $\boldsymbol{B}$ & $\boldsymbol{C}$ & $\boldsymbol{D}$ & $\boldsymbol{E}$ \\
\hline $298-594.18$ & -100889 & 15.3341 & $3.4210 \mathrm{E}-03$ & $2.7966 \mathrm{E}-07$ & -1.8300 \\
$594.18-722.65$ & -104820 & -21.7759 & $-2.6440 \mathrm{E}-03$ & $2.79667 \mathrm{E}-07$ & 5.5800 \\
$722.65-833$ & -76940 & -721.020 & $-6.3519 \mathrm{E}-02$ & 0 & $5.8550 \mathrm{E}+04$ \\
$833-1365$ & -118058 & -57.0652 & $-4.2525 \mathrm{E}-03$ & 0 & 112.645 \\
$298-1365$ & -297496 & 289.970 & $2.36150 \mathrm{E}-03$ & $-9.5700 \mathrm{E}-07$ & -13.9150 \\
\hline
\end{tabular}


solution calorimetry ${ }^{[30-32]}$ are $-101000 \pm 418,-101000 \pm$ 836 , and $-99997 \pm 1255(\mathrm{~J} / \mathrm{mol})$. The Gibbs energy of formation obtained here is in good agreement with the experimental values and with values used earlier by ourselves $^{[5,6]}$ and by Jianrong et al. ${ }^{[4]}$ However, that from
Yamaguchi et al. ${ }^{[30]}$ is about $12 \mathrm{~kJ} / \mathrm{mol}$ more negative since their measured value for $\Delta H_{\mathrm{f}, 298}^{\mathrm{o}}(\mathrm{I})$ is about $12 \mathrm{~kJ} / \mathrm{mol}$ more negative than all the other published values. The fact that they do not fit the measured Gibbs energy of formation would seem to indicate an error in

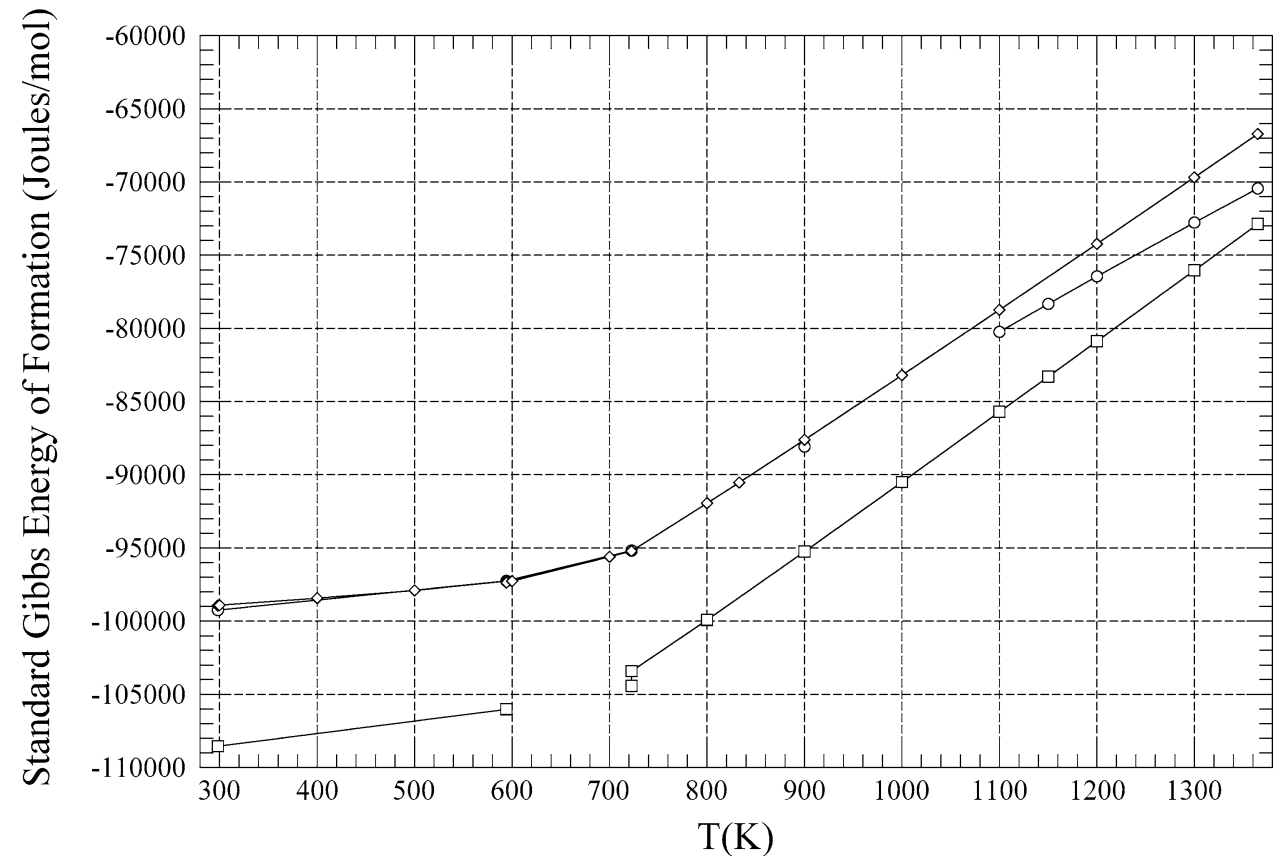

Fig. 5 The standard Gibbs energy of formation of CdTe as a function of temperature. Circles: ref 4, squares: ref 33, and diamonds: present work

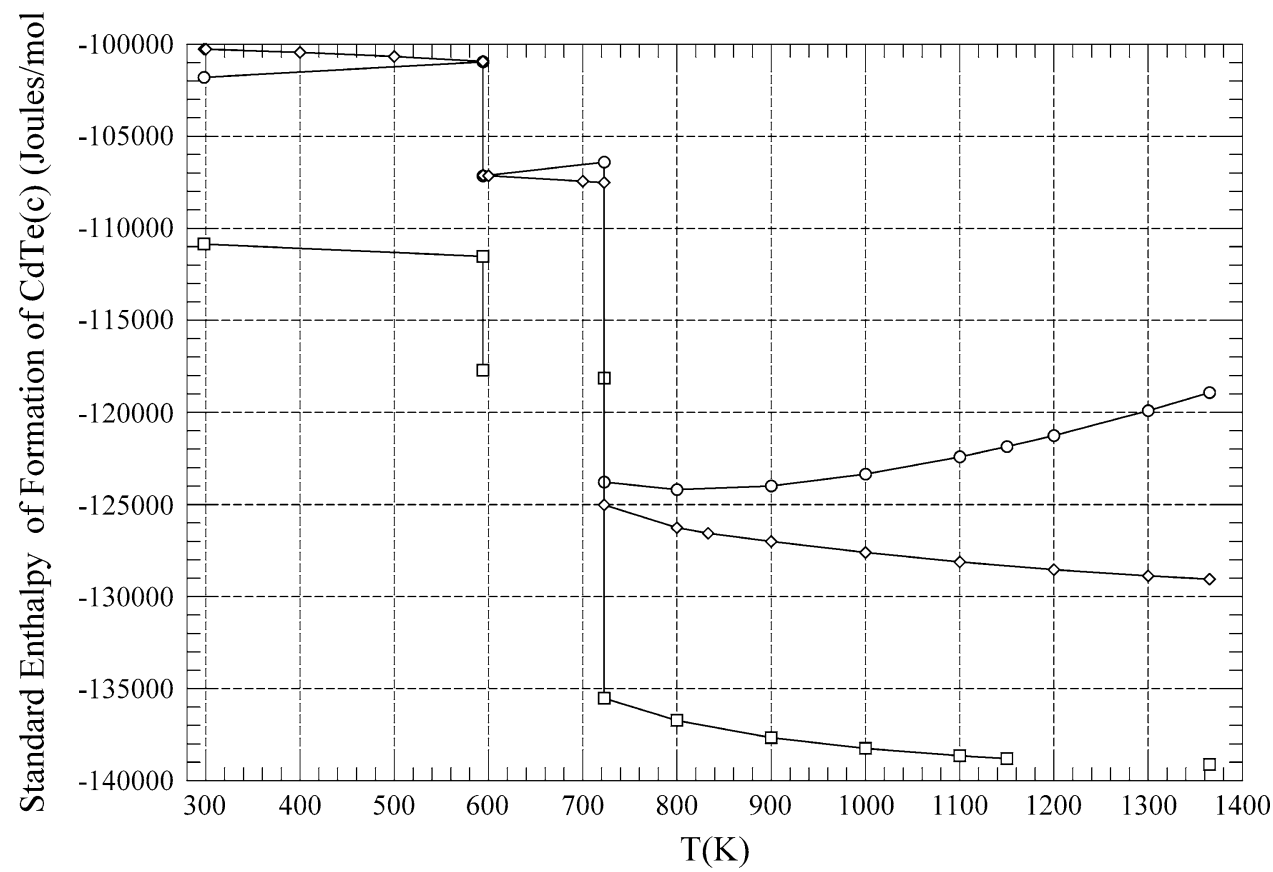

Fig. 6 The standard enthalpy of formation of CdTe as a function of temperature. Circles: ref 4, squares: ref 33, and diamonds: present work 


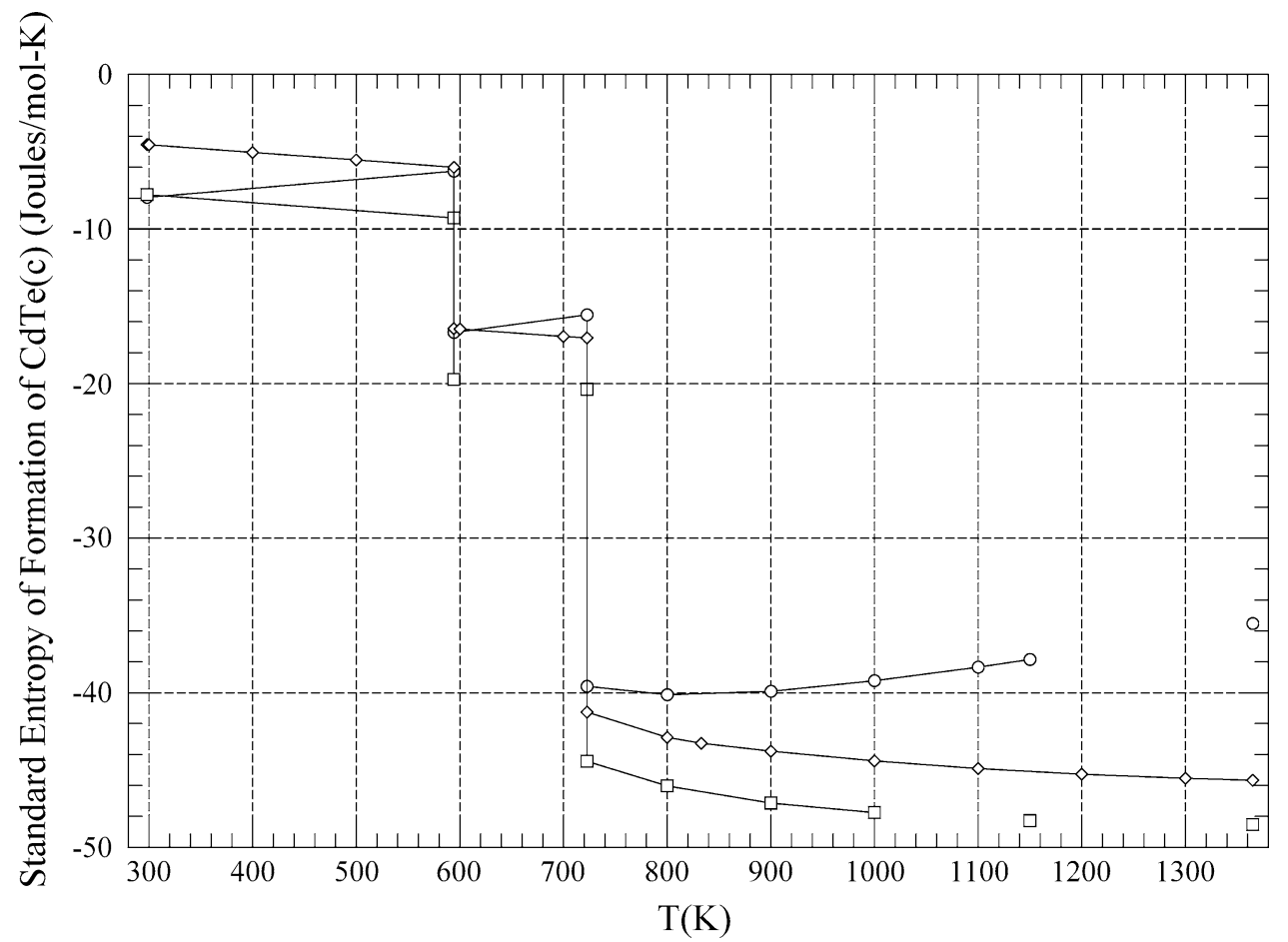

Fig. 7 The standard entropy of formation of CdTe. Circles: ref 4, squares: ref 33, and diamonds: present work

their value of $\Delta H_{\mathrm{f}, 298}^{\mathrm{o}}(\mathrm{I})$. The Gibbs energy is shown in Fig. 5 as a function of temperature. Fig. 6 and 7 show a similar comparison for, respectively, the enthalpy and entropy of formation. Now the results obtained by Jianrong et al. differ significantly at high temperature from those obtained here. At $1365 \mathrm{~K}$, their enthalpy of formation is about $10 \mathrm{~kJ} / \mathrm{mol}$ less negative while the entropy is about $9 \mathrm{~J} / \mathrm{mol} \mathrm{K}$ less negative. As mentioned earlier, this is because they used a heat capacity for CdTe that is about $16 \mathrm{~J} / \mathrm{mol} \mathrm{K}$ greater near $1365 \mathrm{~K}$ than that adopted here. Our earlier ${ }^{[6]}$ analysis of the thermodynamic and phase diagram data for CdTe also used a heat capacity based upon the measurements of Mezaki et al., ${ }^{[8]}$ which have been judged to be too large by Pavlova et al. ${ }^{[3]}$

\section{Conclusions}

The thermodynamic data for $\mathrm{CdTe}(\mathrm{c})$ have been reanalyzed using newer high temperature heat capacities than used before. Although the standard enthalpy and entropy of formation are close to what has been accepted at $298.15 \mathrm{~K}$, they diverge from previous values with increasing temperature. The results obtained here should be a more accurate representation of the thermodynamic properties of the solid, $\operatorname{CdTe}(c)$, which is of value in itself, but they also should be useful in any future analysis of the entire Cd-Te system in that only the model of the liquid phase need be established.

\section{References}

1. A.S. Malkova, Vl.V. Zharov, G.I. Shmoilova, and A.S. Pashinkin, Specific Heats of Zinc and Cadmium Tellurides in the range 360-760 K, Russ. J. Phys. Chem., 1989, 63, p $41-$ 43, English translation

2. K. Yamaguchi, K. Kameda, Y. Takeda, and K. Itagaki, Measurements of the High Temperature Heat Content of the II-VI, and IV-VI(II: Zn, Cd, IV: Sn,Pb, VI:Te) Compounds, Mater. Trans. JIM, 1994, 35(2), p 124-188

3. L.M. Pavlova, A.S. Pashinkin, D.S. Gaev, and A.S. Pak, The Heat Capacity of Cadmium Telluride at Medium and High Temperatures, High Temp. 2006, 44(6), p 843-851; translated from Telofizika Vysokikh Temperatur, 2006, 44(6), p 852-860

4. Y. Jianrong, N.J. Silk, A. Watson, and A.W. Bryant, Thermodynamics and Phase Diagram Assessment of the Cd-Te and Hg-Te Systems, Calphad, 1995, 19(3), p 399-414

5. R.F. Brebrick, C.-H. Su, and P.-K. Liao, Chapter 3, Semiconductors and Semimetals, Vol 19, R.K. Willardson and A.C. Beer, Ed., Academic Press, New York, 1983

6. T.C. Yu and R.F. Brebrick, Supplement, The Hg-Cd-Zn-Te Phase Diagram, J. Phase Equilib., 1993, 14(3), p 271-272

7. K.C. Mills, Thermodynamic Properties of Inorganic Sulfides, Selenides, and Tellurides, Butterworths, London, 1974

8. R. Mezaki, E.W. Tilleux, T.F. Jambois, and J.L. Margrave, High Temperature Thermodynamic Functions for Refractory Compounds, Proc. Symp. Adv. in Thermophysical Properties at Extreme Temperatures and Pressures, Purdue University, 1965, p 135-145

9. R.F. Brebrick, Third Law Analysis of the Crystal-LiquidVapor Equilibrium for Tellurium, High Temp. Sci., 1988, 25, p $187-197$ 
10. R.A. Medzhidov and S.M. Rasulov, Enthalpy and Specific Heat of Tellurium 0 to $750^{\circ}$, Neorganicheskie Materialy, 1975, 11(4), p 646-648

11. A.V. Davydov, M.H. Rand, and B.B. Argent, Review of the Heat Capacity for Tellurium, Calphad, 1995, 19(3), p 375-387

12. R.F. Brebrick, COMMENT on Review of Heat Capacity Data for Tellurium, Calphad, 1997, 21(3), p 335-336

13. R.F. Brebrick and A.J. Strauss, Partial Pressures and Gibbs Free Energy of Formation for Congruently Subliming CdTe(c), J. Phys. Chem. Solid, 1964, 25, p 1441-1445

14. N. Davidson, Statistical Mechanics, McGraw-Hill Book Co, New York, 1962, p 315-321

15. Y.G. Sha, K.T. Chen, R. Fang, and R.F. Brebrick, Second Virial Coefficient and Fugacity of Tellurium Diatomic Molecule $\mathrm{Te}_{2}(\mathrm{~g})$ Near $1273 \mathrm{~K}$, High Temp. Sci., 1988, 25(3), p 153-161

16. C.-H. Su, P.-K. Laio, Y. Huang, S.-S. Liou, and R.F. Brebrick, Interatomic Potentials for $\mathrm{Cd}, \mathrm{Zn}$, and $\mathrm{Hg}$ from Absorption Spectra, J. Chem. Phys., 1984, 81(1), p 11-19

17. J.O. Hirschfelder, C.F. Curtis, and R.B. Bird, Molecular Theory of Gases, John Wiley and Sons, New York, Second Printing, Corrected, with Notes Added, 1964

18. R.F. Brebrick, Partial Pressures in the Cadmium-Telluride and Zinc-Telluride Systems, J. Elect. Soc., 1971, 118, p 2014-2020

19. P. Goldfinger and M. Jeunehomme, Mass Spectrographic and Knudsen Cell Vaporization Studies of Group 2B-6B Compounds, Trans. Farad. Soc., 1963, 59, p 2851-2867

20. R. Hultgren et al., Selected Values of the Thermodynamic Properties of the Elements, American Soc. Metals, Metals Park, OH, 1973

21. N. Arley and K.R. Buch, Chaper 12, Introduction to the Theory of Probabilty and Statistics, Wiley, New York, 1950

22. J.A. Nelder and R. Mead, A Simplex Method for Function Minimization, Comput. J., 1965, 7(4), p 308-313; Errata, Comput. J., 1965, 8(1), p 27
23. R.F. Brebrick, Enthalpy and Entropy Values Deduced from Gibbs Free Energy Measurements, High Temp. Sci., 1976, 8(1), p 11-23

24. A.T. Dinsdale, SGTE Data for the Pure Elements, Calphad, 1991, 15(4), p 317-425

25. J.H. McAteer and H. Seltz, Thermodynamic Properties of the Tellurides of Zinc, Cadmium, Tin, and Lead, J. Am. Chem. Soc., 1936, 58, p 2081-2084

26. G.R. Newns, Physicochemical Study of Group II-VI Semiconductors. Part 2. Thermodynamics of Cadmium Telluride, Research report no. 20959, Part 2, Post Office Research Station, Dollis Hill, London, 1965

27. V.P. Vasil'ev, M.N. Mantonov, and M.A. Bykov, Thermodynamic Properties and Stability of Solid Solutions in the CdTe-HgTe-Te System, Moscow Univ. Chem. Bull., 1990, 45(3), p 5-12

28. J. Terpilowski and E. Rataczak, Thermodynamic Properties of CdSe and CdTe, Bull. De L'Academie Polonaise Des Sci., 1964, XII(6), p 355-358

29. M. Shamsuddin and A. Nasar, Thermodynamic Properties of Cadmium Telluride, High Temp. Sci., 1990, 28, p 245-254

30. M.J. Pool, Calorimetric Investigation of Cadmium, Silver, and Zinc Tellurides, Trans. Metall. Soc. AIME, 1965, 233(9), p 1711-1715

31. P.M. Robinson and M.B. Bever, On the Thermodynamic Properties of the Tellurides of Cadmium, Indium, Tin, and Lead, Trans. Metall. Soc. AIME, 1966, 236(6), p 814-817

32. P.M. Robinson and J.S.L.I. Leach, The Heat Effects Accompanying the Solution in Liquid Bismuth of Tellurium with cadmium, Indium, Tin, or Lead, Trans. Metall. Soc. AIME, 1966, 236(6), p 818-821

33. K. Yamaguchi, K. Hongo, K. Hack, I. Hurtado, and D. Neuschutz, Measurement and Assessment of the Thermodynamic Properties and the Phase Diagram of the Cd-Te System, Mater. Trans. JIM, 2000, 41(7), p 790-798 